\title{
Mathematics Teaching Efficacy Belief and Attitude of Pre-service Teachers and Academic Achievement
}

\author{
Jaime Segarra ${ }^{1 *}$, Carme Julià ${ }^{1}$ \\ ${ }^{1}$ Department of Computer Science and Mathematics, Universitat Rovira i Virgili, Tarragona, SPAIN \\ * Corresponding author: jaimerodrigo.segarra@urv.cat
}

Received: 4 Aug. 2021 Accepted: 17 Oct. 2021

Citation: Segarra, J., \& Julià, C. (2022). Mathematics Teaching Efficacy Belief and Attitude of Pre-service Teachers and Academic Achievement. European Journal of Science and Mathematics Education, 10(1), 1-14. https://doi.org/10.30935/scimath/11381

\begin{abstract}
:
Given the importance of the beliefs and attitudes of the pre-service teachers, this research aims at studying the relation between mathematics teaching efficacy beliefs of pre-service teachers, their attitude towards mathematics and their mathematics academic achievement. Specifically, this work considers both factors together and studies their correlation with mathematics academic achievement. The Mathematics Teaching Efficacy Belief Instrument (MTEBI) is used to measure the teachers' efficacy beliefs of pre-service teachers. Besides, the Attitude towards Mathematics Scale (AMS) is used to rate students' attitude towards mathematics. Participants are 57 pre-service teachers of the third year of the primary education degree. Students of third years of the bachelor's degree were invited to answer the MTEBI and AMS. Obtained results reaffirm that both teachers' efficacy beliefs and attitude towards mathematics are key factors for preservice teacher's mathematics academic achievement. Moreover, the two factors correlate moderately with one another. Furthermore, results manifest that Personal Mathematics Teaching Efficacy (PMTE) is the most determining subscale for academic achievement. It is evidenced the importance of strengthening both the pre-service teachers' efficacy beliefs and the attitude towards mathematics.
\end{abstract}

Keywords: pre-service teachers, mathematics teaching efficacy beliefs, attitude, mathematics academic achievement

\section{INTRODUCTION}

Existing research is concerned about the low mathematical elementary content knowledge of preservice teachers (e.g., Mapolelo \& Akinsola, 2015; Wu et al., 2018). This low mathematical content knowledge might provoke poor results in their mathematical academic achievement. Indeed, in addition to elementary content knowledge of pre-service teachers, there are different variables that were found to impact on academic achievement, such as self-concept (Byrne, 1990), values (Eccles \& Wigfield, 2002), or more cognitive variables, such as learning strategies (Senko \& Miles, 2008) or previous knowledge (Harackiewicz et al., 2002).

In the context of pre-service teachers, authors noticed that some students of the bachelor's degree in primary education present low levels of mathematics teaching efficacy beliefs and a negative attitude towards mathematics (Boaler, 1997; Bursal, 2010). Literature research supports the importance of enhancing the pre-service teachers' mathematics teaching efficacy beliefs (e.g., Bursal, 2010; Moody \& DuCloux, 20015; Yang et al., 2020) and their attitude towards mathematics (e.g., Hourigan \& Leavy, 2019; Michaluk et al., 2018), and how these factors influence to the mathematics academic achievement (e.g., Charalambous et al., 2009; Leavy et al., 2017; Ma \& Kishor, 1997). As pointed out in Hannula (2012), it is still important and interesting to investigate the impact of variables concerning teachers' mathematics related effect on other affective or cognitive variables such as academic achievement. 
However, as far as we are concerned, there is no research taking both mathematics teaching efficacy beliefs and attitude towards mathematics together to study their correlation with mathematics academic achievement. This research aims at studying that correlation. Additionally, six subscales of the two considered factors (two subscales of efficacy beliefs and four subscales of attitude) are studied in order to determine their influence on academic achievement.

\section{Theoretical Framework}

In this section, the definitions of mathematics teaching efficacy beliefs and attitude towards mathematics are revised.

\section{Mathematics teaching efficacy beliefs}

The self-efficacy is one's personal judgment about how well they can deal with a specific situation or task (social cognitive theory) (Bandura, 2001). A person's self-efficacy could influence the effort they put forth in a given situation and how long they persist on a given task (Goddard et al., 2004). According to Bandura, people fear and tend to avoid threatening situations they believe exceed their coping skills, whereas they get involved in activities and behave assuredly when they judge themselves capable of handling situations that would otherwise be intimidating. Efficacy expectations determine how much effort people will expend and how long they will persist in facing obstacles and aversive experiences. The stronger the perceived self-efficacy, the more active the efforts.

Taking into account Bandura's theory (Bandura, 1977, 1997), studies on teachers' efficacy beliefs consider two separate dimensions (Hassan \& Hassan, 2012). The first dimension, personal teaching efficacy, represents a teacher's belief in their skills and abilities to be an effective teacher. The second dimension, teaching outcome expectancy, is a teacher's belief that effective teaching can bring about student learning regardless of external factors such as home environment, family background, and parental influences (Swars et al., 2007).

Some researchers report that there exists relationship between efficacy belief and academic performance in the area of mathematics (e.g., Pajares, 1996). In addition, Perkmen and Pamuk (2011) determine that self-efficacy is a strong predictor of academic achievement in the pre-service teachers and that the outcome expectation is positively related to their academic achievement. Furthermore, Kaya and Cihan (2016) investigate the resources of mathematics self-efficacy and perception of science self-efficacy as predictors of academic achievement. According to their obtained results, resources of mathematics selfefficacy and perception of science self-efficacy are significantly correlated with academic achievement in high levels of influence.

\section{Attitude towards mathematics}

Attitude is a learned disposition or tendency on the part of an individual to respond positively or negatively to some object, situation, concept or another person (Aiken, 1970). Neale (1969) defined attitude to mathematics as an aggregated measure of a liking or disliking of mathematics, a tendency to engage or avoid mathematical activities, a belief that one is good or bad at mathematics, and a belief that mathematics is useful or useless. Attitude refers to a learned tendency of a person to respond positively or negatively towards an object, situation, a concept, or a person. It is also regarded as a belief held by individuals that reflects their opinions and feelings and can be sometimes manifested in behaviour. Attitudes, behaviour, and feelings are interrelated in such a way that people's attitudes determine their behaviour towards objects, situations, and people (Mazana, 2020).

Several researchers suggest that the pre-service teachers should have a positive attitude towards mathematics, because it influences their mathematics academic achievement (e.g., Hemmings, 2010). Moreover, they can have a positive effect on the learning of their students in the future (Cakiroglu \& Isiksal, 2009; Leavy et al., 2017). However, results of previous studies show that teachers of all levels of education often have negative attitudes towards mathematics (e.g., Boaler, 1997; Michaluk et al., 2018). 
Besides, other researchers indicated that primary pre-service teachers, worldwide, possessed negative attitudes towards mathematics and fears about the teaching of mathematics (e.g., Charalambous et al., 2009; Cockcroft, 1982).

\section{Related Work}

As mentioned above, there are several researchers who highlight the importance of studying teachers' efficacy beliefs in teaching mathematics and attitude towards mathematics as both factors significantly influence the students' academic performance (e.g., Auzmendi, 1992; Chang, 2015; Hadley \& Dorward, 2011; Nurlu, 2015).

Hadley and Dorward (2011) study the relationship between the mathematical anxiety of elementary school teachers, mathematics instructional practices, and students' performance in mathematics. They show that low-level beliefs in self-efficacy to teach mathematics could cause mathematical anxiety, which, at the same time, can negatively influence student performance. In addition, they found a positive relationship between mathematics anxiety and anxiety about teaching mathematics. Moreover, they found that the increase in elementary school student performance in mathematics was related to lower levels of anxiety from teaching mathematics, but was not related to general anxiety about mathematics.

The results presented in Nortes and Nortes (2013) show that the attitude towards Mathematics in primary pre-teachers is very low. In addition, the authors indicate that the students perceive the teacher's attitude. Therefore, if the attitude of the teacher is not positive, it negatively influences the attitude of their students.

Nurlu (2015) investigated primary school teachers' characteristics by comparing their mathematics teaching self-efficacy beliefs. The author states that teachers with a greater belief in self-efficacy show a higher level of effort and persistence with students, being more open to new ideas and new methods. In addition, these teachers believe in students' academic achievements and take responsibility for student success.

Chang (2015) examined the relationships between the efficacy of primary math teachers with the selfefficacy and mathematical performance of their students. Their results show that mathematics teachers' beliefs of efficacy have a significant influence on the self-efficacy and performance of their students in mathematics.

Fachrudin et al. (2019) examined Pre-Service Mathematics Teachers' (PSMTs) general knowledge of PISA (Programme for International Student Assessment) and their attitudes and beliefs towards using PISA-based problem in mathematics. The authors revealed the poor score results of PSMTs knowledge of PISA. Additionally, they stated that the teacher education program needs to improve the PSMTs PISA skills and knowledge.

More recently, Yang et al. (2020) studied the relationship between teachers' knowledge, beliefs and instructional practices based on a sample of 495 pre-service mathematics teachers. Results indicated that Chinese pre-service mathematics teachers tend to hold mixed beliefs about the nature of mathematics, and a constructivist view about mathematics teaching and learning, and that they are inclined to report that their teaching is inquiry-oriented.

\section{Objectives and Research Questions}

Taking into account the above presented works, this research aims at studying, on the one hand, the relationship between pre-service teachers' mathematics teaching efficacy beliefs and their attitude towards mathematics with their mathematics academic achievement. Both factors are considered important in the literature, but there is not any work studying both factors together, as far as we are concerned. Additionally, multiple linear regression is used in this research to determine the influence 
Table 1. Distribution of the TLM courses (semester is denoted by S)

\begin{tabular}{|c|c|c|c|c|c|c|}
\hline & \multicolumn{2}{|c|}{ 2nd } & \multicolumn{2}{|c|}{$3 \mathrm{rd}$} & \multicolumn{2}{|c|}{$4^{\text {th }}$} \\
\hline & S3 & S4 & S5 & S6 & S7 & S8 \\
\hline TLM & & TLM1 & TLM2 & & & TLM3 \\
\hline Duration in weeks (and hours) & & 17 (60h) & $17(60 h)$ & & & $17(50 h)$ \\
\hline Tests & & exam & MTEBI and A & & & \\
\hline N (\%) & & & & & & \\
\hline
\end{tabular}

of each studied factor to academic achievement. On the other hand, another goal of this work is to study if there are subscales of the considered factors with which there is a greater correlation with academic achievement. Therefore, the correlation among six subscales of the two factors (two in the case of teaching efficacy beliefs and five in the case of attitude towards mathematics) and mathematics academic achievement is also studied. Specifically, the current study was designed to answer the following questions:

a) How is the correlation between pre-service teachers' mathematics teaching efficacy beliefs, their attitude towards mathematics and their mathematics academic achievement?

b) How is the correlation between the two subscales of mathematics teaching efficacy beliefs, the five subscales of the attitude towards mathematics and the mathematics academic achievement?

\section{METHODOLOGY}

This section presents the methodology adopted in this research.

\section{Participants and Teaching and Learning Mathematics Course}

The sample used in this investigation is a purposive sample (Patton, 2002). The participants in this study are students of the bachelor's degree in Primary Education at University Rovira and Virgili, which consists of a four-year program, composed by eight semesters. The first year of the program contains only introductory pedagogical courses. The Bachelor includes three mandatory courses of Teaching and Learning Mathematics (TLM).

Table 1 shows the distribution of the three TLM courses along the bachelor's degree. It also shows the semester when the mathematical content exam and the MTEBI and AMS were administrated.

The TLM1 course (2nd year) presents the mathematical content pre-service teachers need to know to teach in Primary school. The students have to review mathematical content and processes, and to solve problems. In the TLM2 course (3rd year), the pre- service teachers learn how to use manipulatives and interactive applications to teach Numeracy at Primary school. Finally, in the TLM3 course (4th year), the teacher presents them materials to teach Geometry at Primary school. The sessions of TLM3 consist of Geometry workshops, in which the students work in teams.

During several years, authors noticed low levels of mathematics teaching efficacy beliefs and negative attitudes toward mathematics among pre-service teachers enrolled in the bachelor's degree in primary education. However, there is not any study quantifying those feelings at the current University. Concretely, the most negative feelings and the worst mathematics academic achievement occur during the TLM 1 course, which mainly includes mathematical content. The participants of this study are students of the third year of the Bachelor. They have only coursed the TLM 1 course, which is given during the second year of the Bachelor, as shown in Table 1.

As detailed in short, the mathematics academic achievement was assessed by taken the grade they were given in the TLM 1 course during the 2018-19 academic year. A total of 97 students were enrolled to TLM 1 course. Moreover, students of the third year that attended at the TLM 2 course class at the beginning of the 2019-20 academic year were invited to answer the MTBI and the AMS. Therefore, participation was voluntary and anonymous. Students indicated the initials of their name in order to stablish correspondences with the marks obtained in the TLM 1 course (the marks were provided by 
the corresponding teacher and by using the same code). Once the correspondences were made, all codes were deleted.

Specifically, the participants of this study correspond to 56 students out of the 70 enrolled in the third year of the degree of primary education ( $81 \%$ of the total population), students who attended classes. Notice that only the students that had already attended to the TLM 2 course could be selected for the study. The test was not applied in semesters S3, S6 and S7 because they did not have the TLM course.

Participation in this test was optional. Considering these aspects, it was not necessary to have the consent of the research participants.

\section{Instrument}

As mentioned above, three different instruments were used in this research: 1) the Mathematics Teaching Efficacy Belief Instrument (MTEBI) for pre-service teachers (Enochs et al., 2000), 2) the Attitude towards Mathematics Scale (AMS) for pre-service teachers (Auzmendi,1992), and 3) an exam of mathematical content.

\section{The Mathematics Teaching Efficacy Belief Instrument (MTEBI)}

The Mathematics Teaching Efficacy Belief Instrument (MTEBI) for pre-service teachers results from the modification of the Science Teaching Efficacy Belief Instrument STEBI-B (Enochs \& Riggs, 1990) and aims at reflecting future mathematics teaching beliefs. Indeed, the MTEBI for pre-service teachers has been widely used to measure mathematics teaching self-efficacy and teaching outcome expectancy (e.g., Giles et al., 2016; Moody \& DuCloux, 2015; Newton et al., 2012; Segarra \& Julià, 2020; Swars et al., 2007). The original MTEBI consisted of 21 items in a five-point Likert scale measuring one (strongly disagree) to five (strongly agree). As in Liu et al. (2007), and Segarra and Julià (2020), the third Likert scale item, uncertain, was deleted in the current work to encourage all participants to indicate a level of certainty.

The questions that conform the MTEBI in the case of pre-service teachers are detailed in Table 2. The MTEBI is comprised of two subscales, the personal mathematics teaching efficacy (PMTE) subscale,

Table 2. MTEBI (Mathematics Teaching Efficacy Belief Instrument) for pre-service teachers

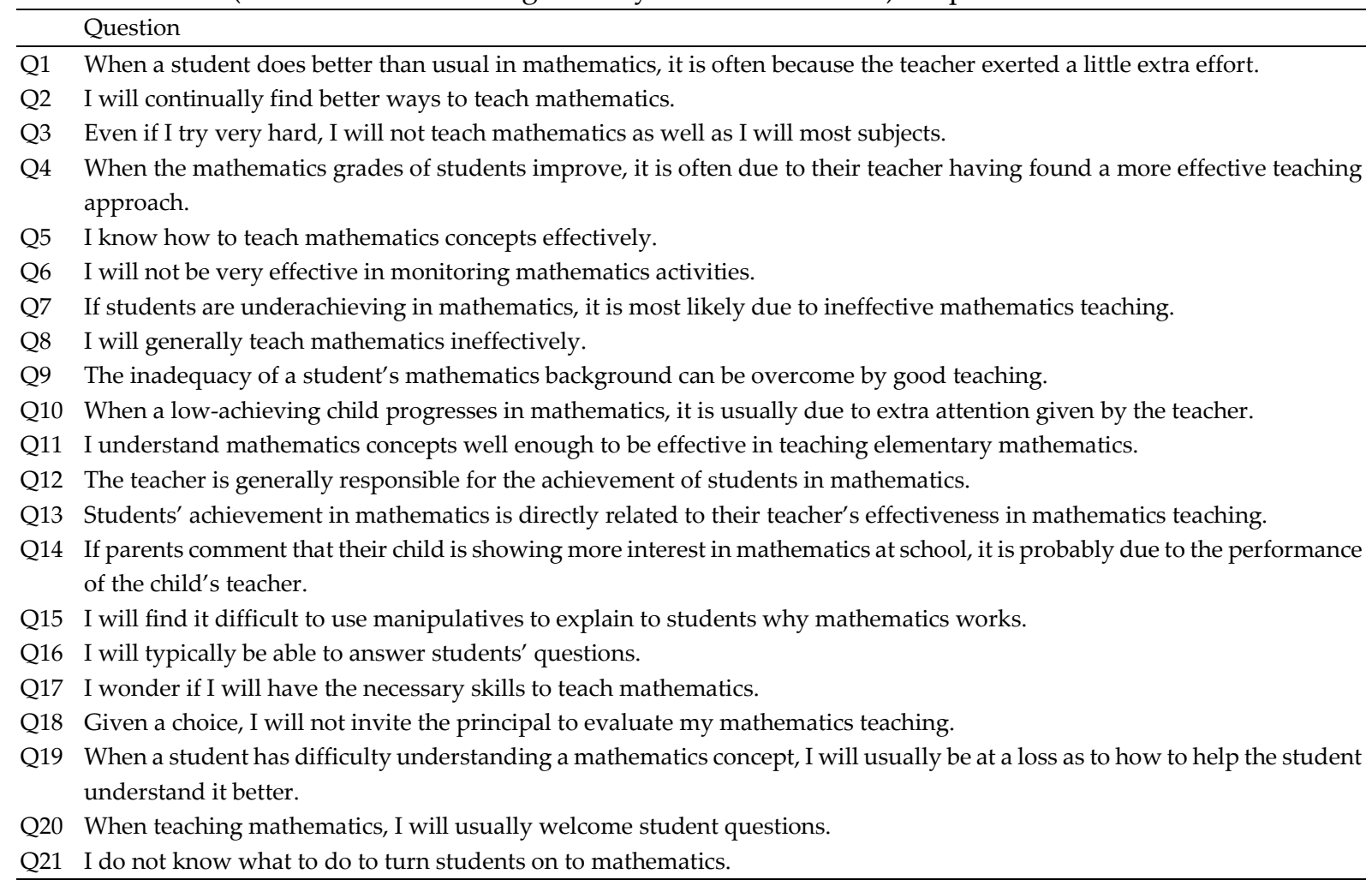


which is composed of 13 items $(2,3,5,6,8,11,15,16,17,18,19,20$, and 21) and Mathematics Teaching Outcome Expectancy (MTOE) subscale, which is composed of 8 items $(1,4,7,9,10,12,13$, and 14). Eight of the items of PMTE are reverse scored $(3,6,8,15,17,18,19$ and 21). The responses corresponding to these items must be inverted before being added into the total PMTE score $(4=1,3=2,2=3$, and $1=4)$.

\section{The Attitude towards Mathematics Scale (AMS)}

There exist different instruments measuring the attitude towards mathematics. Some of them are studied in Aiken (1979), Fennema and Sherman (1979), Auzmendi (1992), Tapia and Marsh (2004), Adelson and McCoach (2011). Auzmendi (1992) drew up one of the most cited attitude scale towards mathematics from those performed in the Spanish language. The author justifies the construction of a new scale in the absence of this type of instrument developed in Spanish and Latin American. The author was inspired by the characteristics that represent a scale of attitudes in Morales (1988). The current research uses the attitude towards the mathematics scale (AMS) proposed in Auzmendi (1992), since it is an instrument designed in Spanish and specifically developed for pre-service teachers.

The AMS has five subscales (pleasure, anxiety, usefulness, motivation and confidence). According to Auzmendi, the pleasure towards mathematics refers to the enjoyment caused by mathematical work. The anxiety towards mathematics refers to the feeling of anxiety, fear that the person manifests in the matter of mathematics. The usefulness subscale refers to the value that a student attaches to mathematics, to the usefulness that he perceives that this subject may have for professional life. The motivation subscale represents how the student feels towards the study and the use of mathematics. Finally, the confidence subscale is the feeling caused by the ability towards mathematics.

The AMS consists of 25 items on a five-point Likert scale that measures from one (strongly disagree) to five (strongly agree) and is used in several investigations (e.g., Fernández, 2010; Morales, 2000; Nortes \& Nortes, 2014). The items of the AMS are detailed in Table 3. As in the MTEBI, the third element of the Likert scale, which was in the original version of the AMS, was removed. As mentioned above, the AMS

Table 3. Attitude towards mathematics scale (subscales and items)

\begin{tabular}{|c|c|c|}
\hline Subscales & & Item \\
\hline \multirow[t]{4}{*}{ Pleasure } & Q4 & Using mathematics is fun. \\
\hline & Q9 & I enjoy talking to others about mathematics. \\
\hline & Q1 & Mathematics is enjoyable and stimulating to me. \\
\hline & Q24 & If I had the chance, I would enroll in more mathematics courses than are required. \\
\hline \multirow[t]{9}{*}{ Anxiety } & Q2 & I am pretty bad at mathematics. \\
\hline & Q3 & Studying or working with mathematics does not scare me at all. \\
\hline & Q7 & Mathematics is one of the subjects that I fear the most. \\
\hline & Q8 & I am confident when I face with a mathematics problem. \\
\hline & Q12 & When I face a mathematics problem, I feel unable to think clearly. \\
\hline & Q13 & I am calm when I face with a mathematics problem. \\
\hline & Q17 & Working with math makes me feel nervous. \\
\hline & Q18 & I do not get upset when I have to work on mathematics problems. \\
\hline & Q22 & Mathematics makes me feel uncomfortable and nervous. \\
\hline \multirow[t]{3}{*}{ Motivation } & Q5 & Mathematics is too theoretical to be of any use to me. \\
\hline & Q10 & $\begin{array}{l}\text { Mathematics can be useful for those who decide to pursue a "science" degree, but not for the rest of the } \\
\text { students. }\end{array}$ \\
\hline & Q25 & The topics taught in math classes is very uninteresting. \\
\hline \multirow[t]{6}{*}{ Usefulness } & Q1 & I consider mathematics to be a very necessary subject in my studies. \\
\hline & Q6 & I want to get a deeper understanding of mathematics. \\
\hline & Q15 & I hope to have little use of mathematics in my professional life. \\
\hline & Q16 & I consider that there are other subjects more important than mathematics for my future profession. \\
\hline & Q19 & I would like to have an occupation in which I had to use mathematics. \\
\hline & Q21 & For my professional future, mathematics is one of the most important subjects I have to study. \\
\hline \multirow[t]{3}{*}{ Confidence } & Q11 & Having good mathematics skills will increase my job prospects. \\
\hline & Q20 & It gives me great satisfaction to be able to solve mathematics problems. \\
\hline & Q23 & If I set my mind to it, I think I would master the mathematics well. \\
\hline
\end{tabular}


Table 4. Cronbach's Alpha

\begin{tabular}{lcc}
\hline & $\alpha$-Cronbach & Meaning \\
\hline MTEBI & 0.75 & Acceptable \\
PMTE & 0.82 & Good \\
MTOE & 0.66 & Questionable \\
AMS & 0.93 & Excellent \\
Pleasure & 0.82 & Good \\
Anxiety & 0.93 & Excellent \\
Motivation & 0.55 & Poor \\
Usefulness & 0.81 & Good \\
Confidence & 0.36 & Unacceptable \\
\hline
\end{tabular}

establishes five subscales: pleasure (items 4, 9, 14 and 24), anxiety (items 2, 3, 7, 8, 12, 13, 17, 18 and 22), motivation (items 5, 10, and 25), usefulness (items 1, 6, 15, 16, 19 and 21) and confidence (items 11, 20 and 23). Ten of the AMS items have a reverse score (items 2, 5, 7, 10, 12, 15, 16, 17, 22 and 25). The answers corresponding to these items must be reversed before being added to the total AMS score $(4=$ $1,3=2,2=3$ and $1=4)$.

\section{Mathematical Content Exam}

Academic achievement in mathematics was assessed during TLM 1 by averaging the scores obtained in different assessment activities. Two of these activities are exams designed to assess the mathematical content knowledge of pre-trained teachers. In addition, they had to be able to explain the problems correctly. Specifically, exams consist of arithmetic and geometry problems. The exams is scored on a scale from 0 up to 10 .

\section{Data Analysis}

In order to determine the reliability of the obtained results, Cronbach's alpha test was applied (Cronbach, 1951). Table 4 shows Cronbach's alpha coefficients for the MTEBI and its two subscales (PMTE and MOTE) and for the AMS and its five subscales (pleasure, anxiety, motivation, usefulness and confidence). Rules proposed in George and Mallery (2003) are considered to interpret the obtained alpha values. In the case of motivation and confidence subscales, the values of Cronbach's alpha are poor and unacceptable, respectively. Due to that, the confidence subscale was eliminated before the analysis. It is important to note that Cronbach's alpha for AMS is excellent and for MTEBI it is acceptable.

In order to identify the correlation method and the regression analysis that can be used in this investigation, we study the contrast of the normal population distribution (Shapiro \& Wilk, 1965). Results of the tests indicate that data normality can be accepted in each of the three groups MTEBI, AMS and academic achievement ( $\mathrm{p}$-value $>0.05$ ) (Shapiro \& Wilk, 1965). Considering these results, the Pearson's correlation coefficient and the multiple linear regression are used in this study.

\section{RESULTS}

This section is organized into two subsections, each of which corresponds to each of the research questions. The first subsection examines the correlation between the pre-service teachers' mathematics teaching efficacy beliefs, their attitude towards mathematics and their mathematics academic achievement. The second subsection studies the correlation between subscales of MTEBI (self-efficacy of the teaching of mathematics and outcome expectancy of the teaching of mathematics), subscales of AMS (pleasure, anxiety, motivation, usefulness and confidence) and mathematics academic achievement. 
Table 5. Mean and standard deviation

\begin{tabular}{lcc}
\hline & $\bar{x}$ & $\sigma$ \\
\hline MTEBI & 3.02 & 0.30 \\
AMS & 2.85 & 0.56 \\
Academic achievement & 5.82 & 1.52 \\
\hline
\end{tabular}

Table 6. Pearson's correlation coefficient between the three pairs of variables

\begin{tabular}{lccc}
\hline & Academic achievement & Teachers' efficacy beliefs & Attitude \\
\hline Academic achievement & 1.00 & & \\
Teachers' efficacy beliefs & $0.66^{* *}$ & 1 & \\
Attitude & $0.60^{* *}$ & $0.47^{* *}$ & 1 \\
\hline
\end{tabular}

*"The correlation is significant $(\mathrm{p}$-value $<0.001)$

Table 7. Multiple linear regression model summary

\begin{tabular}{lccc}
\hline $\mathrm{R}$ & $R^{2}$ & $\mathrm{~F}$ & Sig. \\
\hline 0.73 & 0.54 & 29.56 & 0.000 \\
\hline
\end{tabular}

\section{Correlation Between Mathematics Teaching Efficacy Beliefs, Attitude Towards Mathematics and Mathematics Academic Achievement}

First, the arithmetic mean $(\bar{x})$ and the standard deviation $(\sigma)$ obtained in the MTEBI and AMS are computed. Besides, the marks obtained in the TLM 1 course are collected as mathematics academic achievement. Table 4 shows the arithmetic mean and standard deviation of the MTEBI, the AMS and the academic achievement obtained by the pre-service teachers. Recall that the MTEBI and the AMS are given values up to 4 , while the academic achievement is measured up to 10 .

Table 5 shows that the mean of the MTEBI values is higher than the one obtained in the AMS. In addition, it is observed that the deviation of the AMS is wider than the MTEBI.

Moreover, we study the relationship between the pre-service teachers' efficacy beliefs, attitude towards mathematics and academic achievement through the Pearson's correlation coefficient. Table 6 summarizes the obtained results.

Results shown in Table 6 indicate that there is a significant moderate correlation between teachers' efficacy beliefs and academic achievement, and also between attitude towards mathematics and academic achievement $(0.69>r>0.40)$. In addition, there is a significant moderate correlation between the teachers' efficacy beliefs and between the attitude towards mathematics $(0.69>r>0.40)$.

Finally, a multiple linear regression analysis between the teachers' efficacy beliefs and attitude towards mathematics (independent variable predictors) and mathematics academic achievement (dependent variable) is carried out. Results of the multiple linear regression analysis are shown in Table 7.

The variables teachers' efficacy beliefs and attitude towards mathematics show a significant relationship with academic achievement. The coefficient of determination indicates that $54 \%$ of the variation in the output variable (predicted variable) is explained by the input variables (predictor variables). In other words, the two predictor variables explain $54 \%$ of the change in academic achievement score.

Furthermore, the obtained Standardized Beta Coefficient indicates that the most powerful variable is teachers' efficacy beliefs $(\beta=0.54, p<0.001)$. In the case of the attitude towards mathematics, the Standardized Beta Coefficient is $\beta=0.29, p=0.001$. These values evidence that the two factors predict significantly academic achievement.

\section{Correlation among Subscales of Mtebi, Subscales of Ams and Mathematics Academic Achievement}

This section studies together the two subscales that conform the MTEBI (self-efficacy of the teaching of mathematics and outcome expectancy of the teaching of mathematics) and the four considered from the 
Table 8. Mean, standard deviation, and correlation

\begin{tabular}{lcccc}
\hline & $\bar{X}$ & $\sigma$ & Correlation coefficient $(r)$ & $\mathrm{p}$-value \\
\hline PMTE & 3.17 & 0.30 & 0.72 & $<0.01$ \\
MTOE & 2.87 & 0.45 & 0.16 & 0.11 \\
Pleasure & 2.15 & 0.78 & 0.54 & $<0.01$ \\
Anxiety & 2.81 & 0.69 & 0.57 & $<0.01$ \\
Motivation & 3.28 & 0.57 & 0.27 & 0.024 \\
Usefulness & 2.78 & 0.66 & 0.55 & $<0.01$ \\
\hline
\end{tabular}

Table 9. Multiple linear regression model summary

\begin{tabular}{ccccc}
\hline $\mathrm{R}$ & $R^{2}$ & $R^{2}$ adjusted & $\mathrm{F}$ & Sig. \\
\hline 0.77 & 0.59 & 0.54 & 11.52 & 0.000 \\
\hline
\end{tabular}

AMS (pleasure, anxiety, motivation and usefulness). Recall that the subscale confidence was removed due to the unaccepted reliability provided by Cronbach alpha.

Table 8 shows the arithmetic mean $(\bar{x})$, the standard deviation $(\sigma)$, and the Pearson's correlation coefficient value $(r)$ between the two subscales of MTEBI, the four subscales of the AMS, and academic achievement. It should be noted that the anxiety subscale has been reversed scored. That is, the higher the score is, the less the anxiety.

In addition, in the case of MTEBI, the PMTE subscale has the highest mean. In the AMS, the motivation subscale has the highest mean. The lowest score, on the contrary, is obtained in the pleasure subscale.

Results summarized in Table 8 shows that there is a significant high correlation between the teaching self-efficacy (PMTE) and academic achievement. In the case of the outcome expectation (MTOE), its correlation with the academic achievement is very low and it is not statistically significant. In the case of the AMS subscales, results show that the correlation between both anxiety and usefulness and academic achievement is moderate $(0.70>r>0.39)$. Specifically, the highest correlation with academic achievement is found in the case of the anxiety subscale $(r=0.57, p<0.05)$. The lowest correlation, on the contrary, is obtained between the motivation subscale and academic achievement $(r=0.27)$ and in this subscale, the obtained result is not significant $(\mathrm{p}>0.05)$.

Finally, a multiple linear regression analysis between the six subscales and mathematics academic achievement is carried out taking the independent variables predictors (self-efficacy of the teaching of mathematics, outcome expectancy of the teaching of mathematics, pleasure, anxiety, motivation and usefulness) and the dependent variable (mathematics academic achievement). Table 9 summarizes obtained results.

Results shown in Table 9 indicate that there is a significant dependent relationship between the subscales and academic achievement. The coefficient of determination $\left(R^{2}=0.59\right)$ indicates that $59 \%$ of the variation in the output variable (predicted variable) is explained by the input variables (predictor variables). Therefore, the six predicted variables explain $59 \%$ of the change in academic score. According to the obtained Standardized Beta Coefficient values, the order of influence of the predictor variables on academic achievement is the following: self-efficacy of the teaching of mathematics $(\beta=0.58)$, outcome expectation $(\beta=0.14)$, pleasure $(\beta=0.13)$, anxiety $(\beta=0.08)$, usefulness $(\beta=0.06)$ and motivation $(\beta=0.05)$.

Considering the obtained correlation $(p>0.05)$ and Standardized Beta Coefficient $(\beta=0.13, p>0.05)$, the MTOE subscale is removed from the initial model. Five independent variables predictors (selfefficacy of the teaching of mathematics, pleasure, anxiety, motivation and usefulness) and dependent variable (mathematics academic achievement) define the new model. The values of the new model are equal to model 1, but the Standardized Beta Coefficient values are slightly modified. Again, the most powerful variable is self-efficacy of the teaching of mathematics $(\beta=0.59)$, followed by pleasure $(\beta=$ $0.19)$. 


\section{DISCUSSION}

This research aimed at studying pre-service teachers' mathematics teaching efficacy beliefs, their attitude towards mathematics and their mathematics academic achievement. Besides, it also aimed at studying the correlation between subscales of MTEBI (self-efficacy of the teaching of mathematics and outcome expectancy of the teaching of mathematics), subscales of AMS (pleasure, anxiety, motivation, usefulness and confidence) and mathematics academic achievement.

Regarding the first research question, results reaffirm that there is a significant moderate correlation between the mathematics teaching efficacy beliefs and academic achievement $(r=0.66)$. That is, teachers with greater teachers' efficacy beliefs showed a better academic achievement. This result is in accord with the work presented in Schunk and Mullen (2012), where the self-efficacy is related to mathematics academic achievement. Results also show a moderate correlation between the attitude towards mathematics and academic achievement $(r=0.60)$. This result is consistent with previous research that supports the influence of the attitude towards mathematics of pre-service teachers in their academic achievements in mathematics (Hemmings, 2010). Additionally, results manifest a significant moderate correlation between both factors $(r=0.47)$. This result allows to conclude that both factors are not redundant (its correlation is not high), so they provide different and useful information.

From the multiple linear regression analysis it can be concluded that mathematics teaching efficacy beliefs is the most powerful factor to predict academic achievement $(\beta=0.54)$.

Therefore, this research emphasizes that both positive mathematics teaching efficacy beliefs and a positive attitude towards mathematics of pre-service teachers have a positive effect on their academic achievement.

Concerning the second research question, it is shown that the subscale PMTE presents a significant high correlation with academic achievement $(r=0.72)$. The MTOE subscale, on the contrary, presents a low correlation and it is not significant $(r=0.16, p=0.11)$. These results are consistent with the theoretical predictions based on Bandura's works (Bandura, 1986; 1997), where it is affirmed that self-efficacy beliefs predict academic outcomes. Obtained results also coincide with other previous researches (Kaya, \& Cihan, 2016; Pajares, 1992; Pajares \& Graham 1999; Pajares \& Miller, 1994; Zimmerman, 2000), where authors indicated that there is a relationship between self-efficacy and academic achievement.

The second highest correlation coefficient is obtained between the anxiety subscale and academic achievement $(r=0.57)$. Some researchers also determined that there is a relationship between anxiety and academic achievement (Devine et al., 2012; Pajares \& Miller, 1994; Swars et al., 2006). That is, more anxiety implies less academic achievement.

Results obtained applying a multiple linear regression show that the most powerful variable to predict academic achievement is PMTE subscale $(\beta=0.59)$. The second powerful variable to predict academic achievement is pleasure $(\beta=0.18)$. In the current context, pleasure is the subscale with the lowest given mean. Therefore, a clear implication of this research would be to try to improve the pleasure pre-service teachers feel towards mathematics. According to the obtained results in this research, that improvement will benefit the mathematical academic achievements.

Indeed, considering the impact of the mathematics teaching efficacy beliefs and the attitude towards mathematics with respect to academic achievement, teachers training programs should help pre-service teachers to develop more positive beliefs and attitudes towards mathematics. A clear implication of this research would be to include an evaluation of the mathematics teaching efficacy beliefs and the attitude toward mathematics of the pre-service teachers. Additionally, its evolution throughout the bachelor's degree should also be studied. 
Although this research is focused on a reduced population and a specific context, we believe that the significant relationships found in this investigation allow to extend the same conclusions to a larger population and other contexts.

\section{CONCLUSIONS}

The purpose of this research was to study the relationship between mathematics teachers' efficacy beliefs and attitude towards mathematics of primary pre-service teachers and their academic achievement.

Two instruments were selected to study each of the factors: the MTEBI aims at measuring the teachers' efficacy beliefs, while the AMS aims at assessing the attitude towards mathematics. It should be highlighted that each instrument is composed by subscales (two and four, respectively). This research studies in detail each of the six subscales, in order to determine the correlation between each of them and academic achievement. Unlike the referenced literature, two factors (beliefs and attitude) and their six subscales were studied together in this research.

Results reaffirm that the mathematics teaching efficacy beliefs and the attitude towards mathematics have a significant moderate correlation with academic achievement. Furthermore, the two factors are moderately correlated one to each other. This result confirm that they are not redundant. On the other hand, the multiple linear regression evidence that mathematics teaching efficacy beliefs is more powerful than the attitude towards mathematics to predict mathematics academic achievement.

Additionally, results show that the teaching self-efficacy (PMTE) subscale has the highest correlation with academic achievement of pre-service teachers, followed by the anxiety subscale. The multiple linear regression analysis shows that the PMTE subscale is the most powerful variable to predict academic achievement, followed by pleasure.

This work can be very useful for institutions that design pre-teachers training programs. They can realize that it is important to promote the mathematics teaching efficacy beliefs and the attitude towards the mathematics of their students, since both factors contribute significantly to academic achievement. Furthermore, they can obtain valuable information by analyzing in detail the results obtained in each studied subscales. That analysis would allow to detect possible weakness of students. These weaknesses could be tackled by adapting the curriculum of the degree correspondingly.

A future line of research would be to collect data on beliefs and attitudes towards mathematics considering all the students of the primary education degree and to study their evolution throughout the different academic courses. The idea would be to analyze the beliefs and attitudes towards mathematics at the end of the mathematics teaching and learning courses conforming the degree, to study the impact that the methodological strategies applied in each of them have on these two factors.

\footnotetext{
Author contributions: All authors were involved in concept, design, collection of data, interpretation, writing, and critically revising the article. All authors approve final version of the article.

Funding: The authors received no financial support for the research and/or authorship of this article.

Declaration of interest: Authors declare no competing interest.

Data availability: Data generated or analysed during this study are available from the authors on request.
}

\section{REFERENCES}

Adelson, J., \& McCoach, D. (2011). Development and psychometric properties of the math and me survey: Measuring third through sixth graders' attitudes toward mathematics. Measurement and Evaluation in Counseling and Development, 44(4), 225-247. https://doi.org/10.1177/0748175611418522

\footnotetext{
Aiken, L. (1970). Attitudes towards mathematics. Review of Educational Research, 40, 551-596. https://doi.org/10.3102/00346543040004551

Aiken, L. (1974). Two scales of attitude toward mathematics. Journal for Research in Mathematics Education, 5, 67-71. https://doi.org/10.5951/jresematheduc.5.2.0067
} 
Aiken, L. (1976). Update on attitudes and other affective variables in learning mathematics. Review of Educational Research, 46, 293311. https://doi.org/10.3102/00346543046002293

Auzmendi, E. (1992). Las actitudes hacia la matemática-estadística en las enseñanzas media y universitaria [Attitudes towards mathematics-statistics in middle and university education]. Características y medición. Ed mensajero. Spain.

Bandura, A. (1977). Self-efficacy: Toward a unifying theory of behavioral change. Psychological review, 84(2), 191-215. https://doi.org/10.1037/0033-295X.84.2.191

Bandura, A. (1986). Social foundations of thought and action: A social cognitive theory. Prentice Hall.

Bandura, A. (1997). Self-efficacy: The exercise of control. W.H.

Bandura, A. (2001). Social cognitive theory: An agentive perspective. Annual Review of Psychology, 52(1), 1-26. https://doi.org/10.1146/annurev.psych.52.1.1

Boaler, J. (1997). Setting, social class and survival of the quickest. British educational research journal, 23(5), 575-595. https://doi.org/10.1080/0141192970230503

Bursal, M. (2010). Turkish preservice elementary teachers' self-efficacy beliefs regarding mathematics and science teaching. International Journal of Science and Mathematics Education, 8, 649-666. https://doi.org/10.1007/s10763-009-9179-6

Byrne, B. M. (1990). Self-Concept and Academic Achievement: Investigating Their Importance as Discriminators of Academic Track Membership in High School. Canadian Journal of Education / Revue canadienne de l'éducation, 15(2), 173. https://doi.org/10.2307/1495374

Cakiroglu, E., \& Isiksal, M. (2009). Preservice elementary teachers' attitudes and self-efficacy beliefs toward mathematics. Egitim ve Bilim, 34(151), 132-140.

Chang, Y. (2015). Examining relationships among elementary mathematics teachers' efficacy and their students' mathematics selfefficacy and achievement. Eurasia Journal of Mathematics, Science and Technology Education, 11(6), 1307-1320. https://doi.org/10.12973/eurasia.2015.1387a

Charalambous, C., Panaoura, A., \& Philippou, G. (2009). Using the history of mathematics to induce changes in preservice teachers' beliefs and attitudes: insights from evaluating a teacher education program. Educational Studies in Mathematics, 71, 161-180. https://doi.org/10.1007/s10649-008-9170-0

Charalambous, C., Philippou, G., \& Kyriakides, L. (2008). Tracing the development of preservice teachers' efficacy beliefs in teaching mathematics during fieldwork. Educational Studies in Mathematics, 67(2), 125-142. https://doi.org/10.1007/s10649007-9084-2

Cockcroft, W. H. (1982). Mathematics counts (Report of the committee of enquiry into the teaching of mathematics in schools). Her Majesty's Stationary Office.

Cronbach, L. (1951). Coefficient alpha and the internal structure of tests. Psychometrika, 16, 1-16. https://doi.org/10.1007/BF02310555

Devine, A., Fawcett, K., Szucs, D., \& Dowker, A. (2012). Gender differences in mathematics anxiety and the relation to mathematics performance while controlling for test anxiety. Behavioral and brain functions, 8(1), 8-33. https://doi.org/10.1186/1744-90818-33

Eccles, J. S., \& Wigfield, A. (2002). Motivational beliefs, values, and goals. Annual Review of Psychology, 53, 109-132. https://doi.org/10.1146/annurev.psych.53.100901.135153

Enochs, L., \& Riggs. I. (1990). Further development of an elementary science teaching efficacy belief instrument: A preservice elementary scale. School Science and Mathematics, 90, 695-706. https://doi.org/10.1111/j.1949-8594.1990.tb12048.x

Enochs, L., Smith, P., \& Huinker, D. (2000). Establishing factorial validity of the mathematics teaching efficacy beliefs instrument. School Science and Mathematics, 100(4), 194-202. https://doi.org/10.1111/j.1949-8594.2000.tb17256.x

Fachrudin, A., Widadah, S., \& Kusumawati, I. (2019). Pre-service mathematics teachers' knowledge, beliefs, and attitude toward using PISA-based problem in mathematics education. In Journal of Physics, 1200(1), 1-6. https://doi.org/10.1088/17426596/1200/1/012013

Fennema, E., \& Sherman, J. (1976). Fennema-Sherman mathematics attitudes scales: Instruments designed to measure attitudes toward the learning of mathematics by females and males. Journal for research in Mathematics Education, 7(5), 324-326. https://doi.org/10.2307/748467

Fernández, R. (2010). Actitudes iniciales hacia las matemáticas de los alumnos de grado de magisterio de Educación Primaria: Estudio de una situación en el EEES [Initial attitudes towards the mathematics of elementary school teaching students: Study of a situation in the EEES]. Union, 23, 107-116.

George, D., \& Mallery, P. (2003). SPSS for Windows step by step: a simple guide and reference. Allyn \& Bacon.

Giles, R., Byrd, K., \& Bendolph, A. (2016). An investigation of elementary preservice teachers' self-efficacy for teaching mathematics. Cogent Education, 3(1), 1-11. https://doi.org/10.1080/2331186X.2016.1160523

Goddard, R., Hoy, W., \& Woolfolk, A. (2004). Collective efficacy beliefs: Theoretical developments, empirical evidence, and future directions. Educational researcher, 33(3), 3-13. https://doi.org/10.3102/0013189X033003003 
Hadley, K., \& Dorward, J. (2011). The relationship among elementary teachers' mathematics anxiety, mathematics instructional practices, and student mathematics achievement. Journal of Curriculum and Instruction, 5(2), 27-44. https://doi.org/10.3776/joci.2011.v5n2p27-44

Hannula, M. S. (2012). Exploring new dimensions of mathematics-related affect: Embodied and social theories. Research in Mathematics Education, 14(2), 137-161. https://doi.org/10.1080/14794802.2012.694281

Harackiewicz, J. M., Barron, K. E., Tauer, J. M., \& Elliot, A. J. (2002). Predicting success in college: A longitudinal study of achievement goals and ability measures as predictors of interest and performance from freshman year through graduation. Journal of Educational Psychology, 94(3), 562-575. https://doi.org/10.1037/0022-0663.94.3.562

Hassan, A. \& Hassan, T. (2012). Science teaching self-efficacy and outcome expectancy beliefs of secondary school teachers in UAE. International Journal for Research in Education, 32, 1-22.

Hemmings, B (2010). Prior achievement, effort, and mathematics attitude as predictors of current achievement. The Australian Educational Researcher, 37(2), 41-58. https://doi.org/10.1007/BF03216921

Hourigan, M., \& Leavy, A. M. (2019). The influence of entry route to teaching on Irish pre-service primary teachers' attitudes towards mathematics. Journal of Further and Higher Education, 43(7), 869-883. https://doi.org/10.1080/0309877X.2017.1420148

Kaya, D., \& Cihan, H. (2016). Resources of mathematics self-efficacy and perception of science self-efficacy as predictors of academic achievement. European Journal of Contemporary Education, 18(4), 438-451. https://doi.org/10.13187/ejced.2016.18.438

Leavy, A., Hourigan, M., \& Carroll, C. (2017). Exploring the impact of reform mathematics on entry-level pre-service primary teachers attitudes towards mathematics. International Journal of Science and Mathematics Education, 15(3), 509-526. https://doi.org/10.1007/s10763-015-9699-1

Liu, C., Jack, B., \& Chiu, H. (2008). Taiwan elementary teachers' views of science teaching self-efficacy and outcome expectations. International Journal of Science and Mathematics Education, 6, 19-35. https://doi.org/10.1007/s10763-006-9065-4

Ma, X., \& Kishor, N. (1997). Assessing the relationship between attitude toward mathematics and achievement in mathematics: A meta-analysis. Journal for Research in Mathematics Education, 28(1), 26-47. https://doi.org/10.2307/749662

Mapolelo, D., \& Akinsola, M. (2015). Preparation of mathematics teachers: Lessons from review of literature on teachers' knowledge, beliefs, and teacher education. American Journal of Educational Research, 3 (4), 505-513.

Mazana, M., Montero, C., \& Casmir, R. (2020). Assessing students' performance in mathematics in Tanzania: the teacher's perspective. International Electronic Journal of Mathematics Education, 15(3), 1-28. https://doi.org/10.29333/iejme/7994

Michaluk, L., Stoiko, R., Stewart, G., \& Stewart, J. (2018). Beliefs and attitudes about science and mathematics in pre-service elementary teachers, STEM, and Non-STEM majors in undergraduate physics courses. Journal of Science Education and Technology, 27(2), 99-113. https://doi.org/10.1007/s10956-017-9711-3

Moody, V., \& DuCloux, K. (2015). Mathematics teaching efficacy among traditional and nontraditional elementary pre-service teachers. European Journal of Science and Mathematics Education, 3(2), 105-114.

Morales, E. (2000). Escala de actitudes hacia la estadística (Attitude scale towards statistics). Psicothema, 12(2), 175-178.

Morales, P. (1988). Medición de actitudes en psicología y educación: construcción de escalas y problemas metodológicos [Attitude measurement in psychology and education: Construction of scales and methodological problems]. University of Comillas.

Neale, D. (1969). The role of attitudes in learning mathematics. The Arithmetic Teacher, 16(8), 631-640. https://doi.org/10.5951/AT.16.8.0631

Newton, K., Leonard, J., Evans, B., \& Eastburn, J. (2012). Preservice elementary teachers' mathematics content knowledge and teacher efficacy. School Science and Mathematics, 112(5), 289-299. https://doi.org/10.1111/j.1949-8594.2012.00145.x

Nortes, R., \& Nortes, A. (2013). Actitud hacia las matemáticas en futuros docentes de primaria y de secundaria [Attitude towards mathematics in future primary and secondary school teachers]. Edetania, 44, 47-76.

Nortes, R., \& Nortes, A. (2014). ¿Tienen ansiedad hacia las matemáticas los futuros matemáticos? [Do the future mathematicians have math anxiety?]. Revista de currículum y formación del profesorado, 18 (2), 153-170.

Nurlu, O. (2015). Investigation of teachers' mathematics teaching self-efficacy. International Electronic Journal of Elementary Education, 8(1), 21-40.

Pajares, F. (1996). Self-efficacy beliefs in academic settings. Review of Educational Research, 66(4), 543-578. https://doi.org/10.3102/00346543066004543

Pajares, F., \& Graham, L. (1999). Self-efficacy, motivation constructs, and mathematics performance of entering middle school students. Contemporary Educational Psychology, 24(2), 124-139. https://doi.org/10.1006/ceps.1998.0991

Pajares, F., \& Miller, M. (1994). Role of self-efficacy and self-concept beliefs in mathematical problem solving: A path analysis. Journal of Educational Psychology, 86(2), 193-203. https://doi.org/10.1037/0022-0663.86.2.193

Pajares, M. (1992). Teachers' beliefs and educational research: Cleaning up a messy construct. Review of Educational Research, 62, 307-332. https://doi.org/10.3102/00346543062003307

Patton, M. (2002). Qualitative evaluation and research methods (3rd ed.). Sage. 
Perkmen, S., \& Pamuk, S. (2011). Social cognitive predictors of pre-service teachers' technology integration performance. Asia Pacific Education Review, 12(1), 45-58. https://doi.org/10.1007/s12564-010-9109-x

Schunk, D., \& Mullen, C. (2012). Self-efficacy as an engaged learner. In Handbook of research on student engagement (pp. 219-235). Springer. https://doi.org/10.1007/978-1-4614-2018-7_10

Segarra, J., \& Julià, C. (2020). Mathematics teaching self-efficacy and outcome expectancy of pre-service and in-service primary education teachers. Acta Scientiae, 22(6), 89-108. https://doi.org/10.17648/acta.scientiae.6049

Senko, C., \& Miles, K. M. (2008). Pursuing their own learning agenda: How mastery-oriented students jeopardize their class performance. Contemporary Educational Psychology, 33, 561-583. https://doi.org/10.1016/j.cedpsych.2007.12.001

Shapiro, S., \& Wilk, M. (1965). An analysis of variance test for normality (complete samples). Biometrika, 52 (3), 591-611. https://doi.org/10.1093/biomet/52.3-4.591

Swars, S., Daane, C., \& Giesen, J. (2006). Mathematics anxiety and mathematics teacher efficacy: What is the relationship in elementary preservice teachers? School Science and Mathematics, 106(7), 306-315. https://doi.org/10.1111/j.19498594.2006.tb17921.x

Swars, S., Hart, L., Smith, S., Smith, M., \& Tolar, T. (2007). A longitudinal study of elementary pre-service teachers' mathematics beliefs and content knowledge. School Science and Mathematics, 107(8), 325-335. https://doi.org/10.1111/j.19498594.2007.tb17797.x

Tapia, M., \& Marsh, G. E. (2004). An instrument to measure mathematics attitudes. Academic Exchange Quarterly, 8(2), 16-22.

Wu, L., Chao, L., Cheng, P., Tuan, H., \& Guo, C. (2018). Elementary teachers' perceptions of their professional teaching competencies: Differences between teachers of math/science majors and non-math/science majors in Taiwan. International Journal of Science and Mathematics Education, 16(5), 877-890. https://doi.org/10.1007/s10763-017-9821-7

Yang, X., Kaiser, G., König, J., \& Blömeke, S. (2020). Relationship between pre-service mathematics teachers' knowledge, beliefs and instructional practices in China. ZDM Mathematics Education, 52, 281-294. https://doi.org/10.1007/s11858-020-01145-x

Zimmerman, B. (2000). Self-efficacy: An essential motive to learn. Contemporary Educational Psychology, 25(1), 82-91. https://doi.org/10.1006/ceps.1999.1016 